\title{
Infantile Aortic Coarctation in an Adult with Heart Failure
}

\author{
Eva Rumiz Ernesto Valero Juan Vicente Vilar Enrique Santas Javier Haba \\ Department of Cardiology, Hospital Quirón, Valencia, Spain
}

\author{
Keywords \\ Aortic coarctation - Bicuspid aortic valve $\cdot$ Heart failure . \\ Hypertension
}

\begin{abstract}
Objective: The aim of this case report is to highlight the importance of excluding aortic coarctation in a patient with a bicuspid aortic valve. Clinical Presentation and Intervention: A 56-year-old woman with hypertension was admitted complaining of progressive dyspnea. Transthoracic echocardiography showed a calcified, bicuspid aortic valve with severe stenosis. Aortography revealed the presence of severe narrowing of the aorta between the carotid and subclavian arteries. The patient was referred for cardiovascular surgery in which successful aortic valve replacement and aortic correction were performed. Conclusion: This case report shows an uncommon finding of infantile aortic coarctation in an adult patient admitted with heart failure.
\end{abstract}

(C) 2016 S. Karger AG, Basel

\section{Introduction}

Aortic coarctation (AoC) is the fifth most common congenital cardiac anomaly, presenting in 3 of 10,000 live births [1], and it is defined as a narrowing of the aortic lumen that causes a significant intrastenotic gradient.
This focal narrowing constitutes an aortopathy that may present in a wide range of anomalies of the aortic arch and the abdominal aorta, from mild stenosis to even long hypoplastic segments. The most common location of AoC is near the insertion of the ductus arteriosus remnant in the proximal portion of the descending aorta, distal to the origin of the left subclavian artery [2]. AoC is classified into 2 different types based on its anatomical location: preductal or infantile and postductal, which is the most common form of presentation in adults [3]. Hence, the objective was to report such a case in order to emphasize the importance of excluding the presence of AoC in patients with a bicuspid aortic valve, even in old age.

\section{Case Report}

A 56-year-old woman who presented with a history of hypertension was admitted to our hospital complaining of progressive dyspnea for the last 6 months. Physical examination revealed the presence of a pansystolic murmur at the aortic focus with irradiation to the carotid arteries and pulmonary rales. Electrocardiography showed signs of left ventricle hypertrophy. Laboratory results showed an elevated N-terminal pro-brain natriuretic peptide level, and a chest X-ray showed signs of pulmonary interstitial edema. The patient was admitted to the Department of Cardiology with a diagnosis of acute decompensated heart failure. Transthoracic echocardiography showed left ventricle hypertrophy with a normal left ventricle ejection fraction and a calcified, bicuspid aortic valve with severe stenosis (mean gradient $50 \mathrm{~mm}$

\begin{tabular}{ll}
\hline KARGER & ( ) 2016 S. Karger AG, Basel \\
$\begin{array}{l}\text { E-Mail karger@karger.com } \\
\text { www.karger.com/mpp }\end{array}$ & $\begin{array}{l}\text { This is an Open Access article licensed under the terms of the } \\
\text { Creative Commons Attribution-NonCommercial 3.0 Un- } \\
\text { ported license (CC BY-NC) (www.karger.com/OA-license), } \\
\text { applicable to the online version of the article only. Distribu- } \\
\text { tion permitted for non-commercial purposes only. }\end{array}$
\end{tabular}

Eva Rumiz, MD

Department of Cardiology, Hospital Quirón

Av. Blasco Ibañez No. 14

ES-46920 Valencia (Spain)

E-Mail evarumiz@hotmail.com 
Fig. 1. Transesophageal echocardiography showing a bicuspid aortic valve in systole (a) and diastole (b) with a severe limitation at its opening.
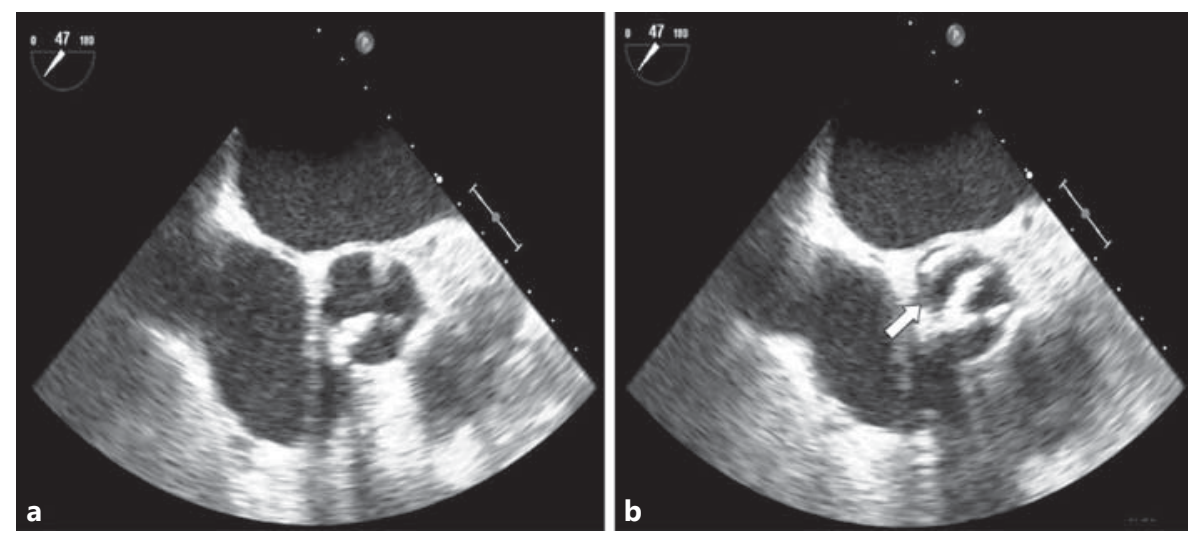

Fig. 2. Coronary angiography. a Initial left transradial approach revealing a severe narrowing of the aorta just before the left subclavian artery take-off (arrow). b Right transradial approach confirming the aortic coarctation (arrow) with an uncommon preductal location. In addition, we observed bilateral rib notching or Roesler's sign (arrowheads)
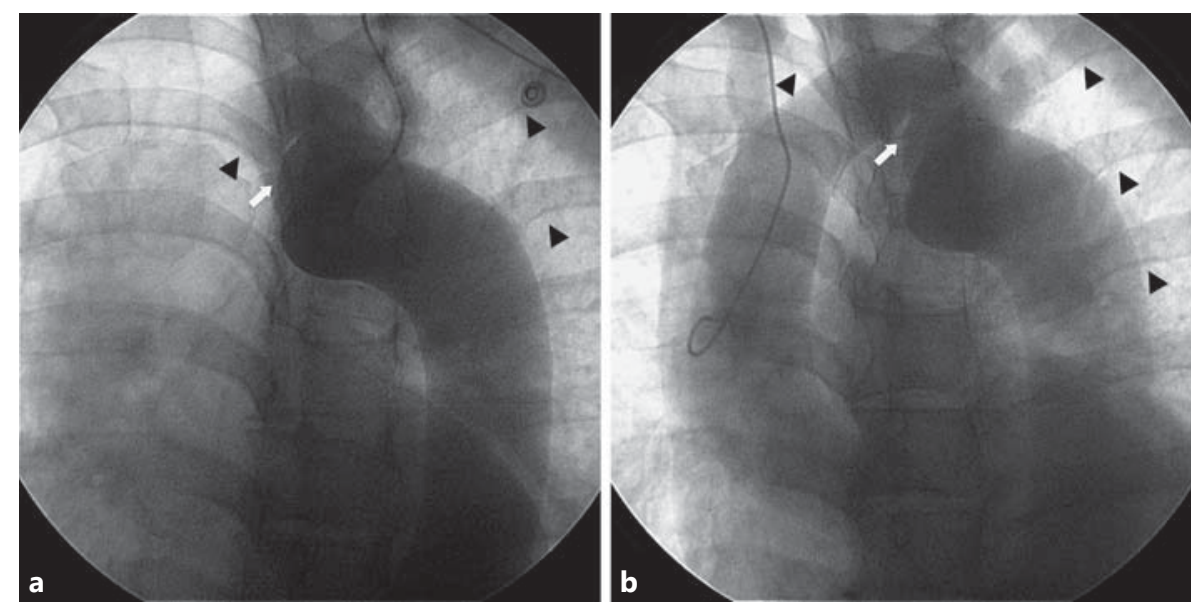

$\mathrm{Hg}$ ). The ascending aorta had a normal width. Transesophageal echocardiography confirmed the presence of a bicuspid aortic valve with severe stenosis (Fig. 1). Coronary angiography, requested per protocol prior to cardiac surgery, was performed initially via the left transradial approach, but it was not possible to advance the guide wire through the aortic arch and into the ascending aorta; aortography at this level revealed the presence of severe narrowing of the aorta just before the origin of the left subclavian artery (Fig. 2a). The presence of AoC was confirmed via the right transradial approach (Fig. 2b) with a significant intrastenotic gradient $(25 \mathrm{~mm} \mathrm{Hg}$ ). In addition, bilateral rib notching or Roesler's sign was observed (arrowheads in Fig. 2). Thoracic computed tomography confirmed the aortographic findings (Fig. 3). The case was discussed within the hospital heart team. Due to the presence of a bicuspid aortic valve and the patient's age, we initially rejected percutaneous transcatheter aortic valve implantation as the treatment of choice for this patient. Concerning AoC correction, due to its location and anatomical characteristics, it was decided to perform the surgical intervention in 2 different procedures. First, mechanical aortic valve replacement was performed successfully, and second, AoC surgical correction via the left thoracotomy approach was implemented during the immediate follow-up. The 6-month follow-up was uneventful and the patient experienced important clinical improvement during outpatient visits.

\section{Discussion}

This case report shows the uncommon finding of asymptomatic AoC in an adult female with a diagnosis of aortic bicuspid valve with severe stenosis and therefore highlights the importance of screening for this anomaly in such patients.

AoC is a relatively frequent congenital anomaly, accounting for $5-7 \%$ of all congenital cardiovascular diseases. The presence of a bicuspid aortic valve is the cardiac anomaly most frequently associated with AoC, occurring in more than $50 \%$ of cases, whereas its prevalence in the general population is only $1-2 \%$. It is also noteworthy that both coarctation and bicuspid aortic valves occur more frequently in males, with a prevalence of approximately $4: 1$. The clinical presentation is variable, from asymptomatic adulthood cases to progressive heart failure and death at an early childhood age, depending on the location and extent of the aortic stenosis and its association with other cardiac anomalies. 

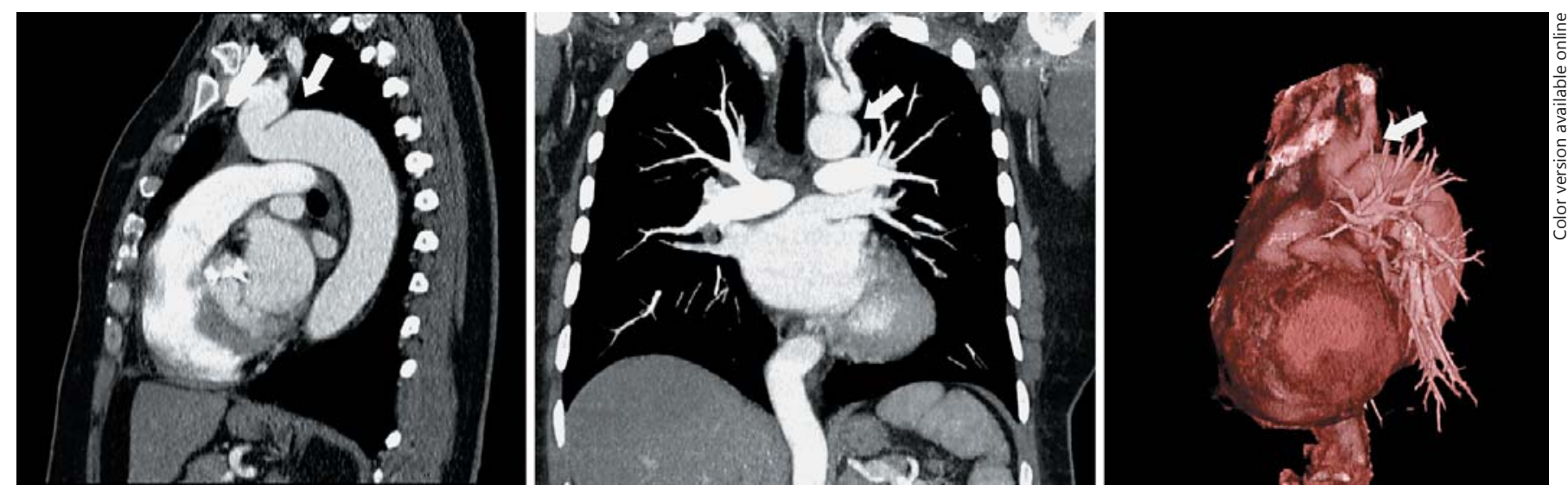

Fig. 3. Thoracic computed tomography confirming the aortic coarctation (arrow) with an uncommon preductal location.

Generally, AoC is diagnosed in childhood and it is very rarely diagnosed beyond the fourth decade of life because the survival of patients with a noncorrected severe AoC is impaired, with mortality rates as high as $75 \%$ in that decade of life and $90 \%$ at the end of the fifth decade of life [4]. It is worth mentioning that our 56-year-old patient was asymptomatic until this index admission for heart failure, probably due to dilated intercostal collateral vessels which constitute a way to bypass the coarctation and supply the descending aorta. The dilated and tortuous vessels erode the inferior margins of the ribs, resulting in the notching (Roesler's sign) seen only in long-standing cases.

AoC is thought to occur at the time of ductal closure due to contraction and fibrosis of anomalous circumferential fibroductal tissue that pulls the posterior aortic shelf towards the contralateral wall. However, its etiology is still unclear, and it has been postulated that, rather than a focal vascular stenosis, this anomaly might be part of a generalized vasculopathy. This hypothesis could be justified by its frequent association with other vascular anomalies, such as aortic aneurysms or intracranial malformations, and other congenital cardiovascular diseases, such as bicuspid aortic valves [5], ventricular septal defects, patent ductus arteriosus, transposition of the great arteries, persistent truncus arteriosus [6], atrioventricular canal defects, or left-sided obstructive heart defects, including hypoplastic left heart syndrome.

In our patient the AoC is probably preductal, since the ductal location is normally distal to the left subclavian artery, although imaging techniques were unable to identify the ductal remnant. The postductal AoC constitutes the most common type of AoC diagnosed during adult- hood; nevertheless, this case exemplifies an extremely rare location in an adult. This is because in a high percentage of cases it is associated with other congenital anomalies, leading to a worse prognosis at a young age. In those uncommon cases of patients who enter adulthood undiagnosed, hypertension is the most common presenting symptom [7]; others may complain of frequent headaches or claudication of the lower extremities with exertion [8].

Preductal AoC in adulthood is a very rare finding; however, the diagnosis of bicuspid aortic valve requires its exclusion, even at an advanced age. Bicuspid aortic valve and $\mathrm{AoC}$ are two cardiovascular anomalies that appear in cahoots with a similar pathophysiology and are part of a diffuse arteriopathy.

\section{Conclusion}

This case report showed an uncommon finding of an infantile AoC in an adult patient with a bicuspid aortic valve and severe stenosis, highlighting the importance of screening for this anomaly in such patients.

\section{Disclosure Statement}

None. 


\section{References}

1 Erbel R, Aboyans V, Boileau C, et al: 2014 ESC guidelines on the diagnosis and treatment of aortic diseases: document covering acute and chronic aortic diseases of the thoracic and abdominal aorta of the adult. The Task Force for the Diagnosis and Treatment of Aortic Diseases of the European Society of Cardiology (ESC). Eur Heart J 2014;35:2873-2926.

2 O'Brien P, Marshall AC: Coarctation of the aorta. Circulation 2015;131:e363-e365.
3 Holloway BJ, Rosewarne D, Jones RG: Imaging of thoracic aortic disease. Br J Radiol 2011; 84:S338-S354.

4 Bhatt AB, Foster E, Kuehl K, et al: Congenital heart disease in the older adult: a scientific statement from the American Heart Association. Circulation 2015;131:1884-1931.

5 Warnes CA: Bicuspid aortic valve and coarctation: two villains part of a diffuse problem. Heart 2003;89:965-966.
6 Selvan JP, Uthaman B, Abushaban L, et al: Long-term follow-up of persistent truncus arteriosus: Kuwait experience. Med Princ Pract 2012;21:277-281.

7 Strafford MA, Griffiths SP, Gersony WM: Coarctation of the aorta: a study in delayed detection. Pediatrics 1982;69:159-163.

8 Torok RD, Campbell MJ, Flemming GA, et al: Coarctation of the aorta: management from infancy to adulthood. World J Cardiol 2015;7: 765-775. 